\title{
The Effect of Ramadan Fasting on Oral Anticoagulant: Experience of Tertiary Academic Hospital
}

\author{
Fakhr AlAyoubi ${ }^{1 *}$, Shereen Dasuqi ${ }^{1}$, Samha AlAyoubi ${ }^{2}$ and Ahmad Hayajneh ${ }^{3}$ \\ ${ }^{1}$ Department of Clinical Pharmacy Services, King Khalid University Hospital, King Saud University Medical City, Saudi Arabia \\ ${ }^{2}$ Department of Basic science unit Cardiac, King Fahad Cardiac Center, King Saud University, Saudi Arabia \\ ${ }^{3}$ Department of Nursing, King Fahad Cardiac Center, King Saud University Medical city, Saudi Arabia
}

Submission: March 18, 2021; Published: April 07, 2021

"Corresponding author: Fakhr AlAyoubi, Department of Clinical Pharmacy Services, King Khalid University hospital, King Saud University Medical City, Riyadh, Saudi Arabia

Abstract

Introduction: Direct oral anticoagulants (DOACs) have been approved for stroke prevention in non-valvular atrial fibrillation (AF). The outcomes achieved by clinical trials depend on pharmacokinetics and pharmacodynamics of these drugs which are used orally in regular doses once or twice daily. During our routine practice we face an obligatory choice to prescribe NOAC twice daily during the month of Ramadan. Twice daily dose drugs in our practice as well as with Muslim patients everywhere in the world during the holy month of Ramadan.

Objective: to evaluate the effectiveness and safety of NOACs either once daily or twice daily used during the month of Ramadan for stroke prevention in Non-Valvular atrial fibrillation.

Methods: An observational study in tertiary university hospital at Saudi Arabia for 114 patient's non-valvular atrial fibrillation on NOACs during the month of Ramadan 1441 H/ 2019 with laboratory follow ups before Ramadan and one month after for each patient who completed at least 15 days fasting during this Holy month of Ramadan 1441 H/ 2019.

Results: 114 patients, 40 were on Rivaroxaban and 74 on Dabigatran, the baseline characteristic are similar except the history of myocardial infarction 28\%, and Heart failure 58\% in the Rivaroxaban arm which was higher than the Dabigatran arm 9\%, \& 12\%. Regarding the concomitant medications used Aspirin in Rivaroxaban arm 33\%, Dabigatran arm 11\%, NSAID only Dabigatran arm 8\%, \%, no significant deferent in the stroke and bleeding events between two arms.

Conclusion: The data shows that the Direct oral anticoagulant are effective and safe to be used in Ramadan for non-valvular atrial fibrillation regardless the frequency of anticoagulant, further studies are needed to support these findings in non-valvular atrial fibrillation and other indications.

Keyword: Anticoagulant; Rivaroxaban; Dabigatran; Direct oral anticoagulant (DOAC); Ramadan; Fasting; Bleeding; Efficacy; Stroke prevention; Safety of direct oral anti-coagulant; non-valvular atrial fibrillation

Abbreviations: DOAC: Direct Oral Anticoagulant; AF Atrial Fibrillation; NOAC's: Non-Valvular Atrial Fibrillation; TIA: Transient Ischemic Attack

\section{Introduction}

Around the world, the Muslim population performs fasting of the ninth month of the Islamic lunar calendar (Ramadan) every year. Fasting during the month of Ramadan, includes food, beverage, smoking, as well as all oral drugs with some restrictions for intravenous drugs to be restriction from dawn until sunset. Ramadan migrates throughout the seasons due to the Islamic lunar calendar year is shorter than the solar year by 10 to 11 days. Most Muslims change their lifestyle during Ramadan, including dietary 
and sleep pattern $[1,2]$ leading to change in the hemodynamic profile for Ramadan fasters. Fasting Ramadan has a significant metabolic, hormonal, and inflammatory changes [3]. Dehydration was confirmed on Ramadan faster during the daylight hours but in summertime [4]. Although fasting Ramadan has a positive impact on fasting blood glucose and serum lipid profile [5,6]. The effectiveness of oral drugs may be changed during Ramadan, especially renal excreted drugs [7-9]. As the dehydration may decrease renal function, which will increase the toxicity of renal excreted drugs.

\section{Methods}

We conducted an observational cohort study at King Saud University Medical City (KSUMC), Riyadh, Saudi Arabia. The study included all patients with non-valvular atrial fibrillation on direct oral anticoagulant during Ramadan 1440Higri calendar.

a) Inclusion criteria: Patients with non-valvular Atrial Fibrillation documented by ECG,CHA2 DS2 VASc 1 or more and treated with Rivaroxaban or Dabigatran started at or before 1st of Shaban $1440 \mathrm{H}$ which is one month before Ramadan. Each patient included in the study had to be fasting at least 15 days during the Holy month of Ramadan.

b) Exclusion criteria: Active liver disease, Pregnancy, Patient with transient ischemic attack (TIA), stroke or major bleeding within 14 days of recruitment, Patient with non-valvular A. Fib Received warfarin.

In order to study the effectiveness of direct oral anticoagulant for Ramadan fasting patients, we calculate the incidence of the clinical outcomes before the start of fasting and 1 month after fasting.

Data were analyzed using the SAS version 9.2 (SAS Institute, Inc, Cary, NC) for Windows ${ }^{\circledR}$. With $p$-value of $<0.05$ considered statistically significant. Descriptive statistics are reported mean and medians \pm standard deviation or as frequencies and percentages, as appropriate. Chi-squared tests were used to determine association between qualitative variables.

\section{Discussion}

During Ramadan fasting thru the daylight hours, practicing Muslims are undoubtedly dehydrating at a rate that is determined by the loss of body water minus the amount of metabolic water that is produced over this period. Losses in body mass over a long period, any other changes in body composition may bias the calculation. Many studies showed that the daytime urine osmolality tended to increase progressively throughout the month of intermittent fasting and it was even higher before breaking the fast especially if the fasting hours exceeded the 12 hours which is the case in summer time [10]. As recommended by the International Diabetes Federation and Diabetes and Ramadan International Alliance, patient on Chronic dialysis or chronic kidney disease stages 3-5 are considered to be at very high risk and high-risk categories, respectively, and are exempted from fasting $[11,12]$. Fasting for one month in Ramadan (June- July 2015, Rize, Turkey) for approximately 17.5 hours each day was not associated with worsening of renal functions in patients with Stage 3-5 CKD. These findings were similar to the results from other observational studies both in patients with CKD and renal transplantation. However, elderly patients may still be under a higher risk [13].

The study showed a significant association between fasting Ramadan and stroke as an independent risk factor for stroke, and specifically ischemic stroke [14]. Atrial fibrillation is a type of irregular heartbeat. It means that the heart may not be pumping as well as it should. As a result, blood clots are more likely to form in the heart, if a clot blocks one of the arteries leading to the brain, it could cause a stroke or transient ischemic attack (TIA). So, the direct oral anticoagulant one of the way to reduce the risk of a stroke by decrease risk of blood clots forming, [15] and have been approved for stroke prevention in non-valvular atrial fibrillation [16]. In all patients with AF, the CHA2DS2-VASc score should be systematically assessed to identify the risk of stroke and to decide on the initiation of appropriate direct oral anticoagulation therapy accordingly. Technology tools may assist in this undertaking. Oral anticoagulation therapy is recommended in all male patients with CHA2DS2-VASc score of 2 or more, and in all female patients with a score of 3 or more. Oral anticoagulation therapy should be considered in male patients with CHA2DS2-VASc score of 1 and in female patients with a score of 2 , considering individual characteristics and patient preferences. When initiating anticoagulation, a non-vitamin $\mathrm{K}$ antagonist (DOAC) which include (Dabigatran, Rivaroxaban, Apixaban, and Edoxaban) are recommended over warfarin in DOAC-eligible patients with $\mathrm{AF}$ (except with moderate-to-severe mitral stenosis or a mechanical heart valve) [17].

Patient who treated with warfarin during Ramadan, has risk to develop supra-therapeutic INR [17-19]. The outcomes achieved by clinical trials for direct oral anticoagulant depend on pharmacokinetics and pharmacodynamics of these drugs which are used orally in regular doses once or twice. Across many diseases, studies have shown that patients taking medication at specific times of day may make the therapy more effective [20-23]. In Riyadh, Ramadan falls at summer at the time of this study. Adult Muslims who join the holy fast will refrain from taking any food, beverages, or oral drugs between dawn and sunset for up to 15 to19 hours a day. In fact, drug doses can be taken only between sunset and dawn, and the time span between them is shorter than outside Ramadan. It is therefore not surprising that potentially invasive studies have been challenging to conduct, leading to a relative paucity of direct evidence regarding the physiological effects of Ramadan fasting. However, over the past few years some studies examining glucose metabolism, lipid profiles, circadian rhythms, sleep, and aspects of hormone physiology during Ramadan have been performed, hypertension and small few studies for stroke in fasting patients. 
The objective of this study is to evaluate the effectiveness and safety of direct oral anticoagulant used by Ramadan fasting Muslim patients for stroke prevention in non-valvular atrial fibrillation at King Saud University Medical City (KSUMC), Riyadh, Saudi Arabia. There is retrospective, observational study, supplemented with physician and patient questionnaires, with data captured before, during and after Ramadan that revealed $64 \%$ of diabetic patients reported fasting everyday of Ramadan and $94.2 \%$ fasted for at least 15 days [24]. The dehydration may be a significant risk factor for the physically and economically costly outcome of ischemic stroke and reinforces the need to better understand how dehydration increases the risk of ischemic stroke especially in patients at higher risk of stroke due to comorbid conditions such as atrial fibrillation [25]. There is a study conducted in Turkey concluded that although Ramadan fasting had an adverse effect on diabetic patients with ischemic stroke, there was no negative effect on stroke frequency, and the hypertensive hemorrhagic stroke ratio is lower [26]. There is a small study that was conducted in the State of Qatar in the Arabian Gulf demonstrated that no significant difference was found in the number of hospitalizations for stroke while fasting during the month of Ramadan when compared to the non-fasting months [27].

\section{Result}

Out of two hundred thirty-four (234) patients visiting KSUMC anticoagulant clinics receiving Dabigatran or Rivaroxaban during the past three months before Ramadan 1441 H/ 2019 , only 114 patients are eligible to our study. 120 patients were excluded duo to various reasons (Figure 1). There is no clinically significant in Laboratory values before and after fasting in patients who received Dabigatran or Rivaroxaban (Table 1-4).

1535 pts follow up in articoagulant clinics

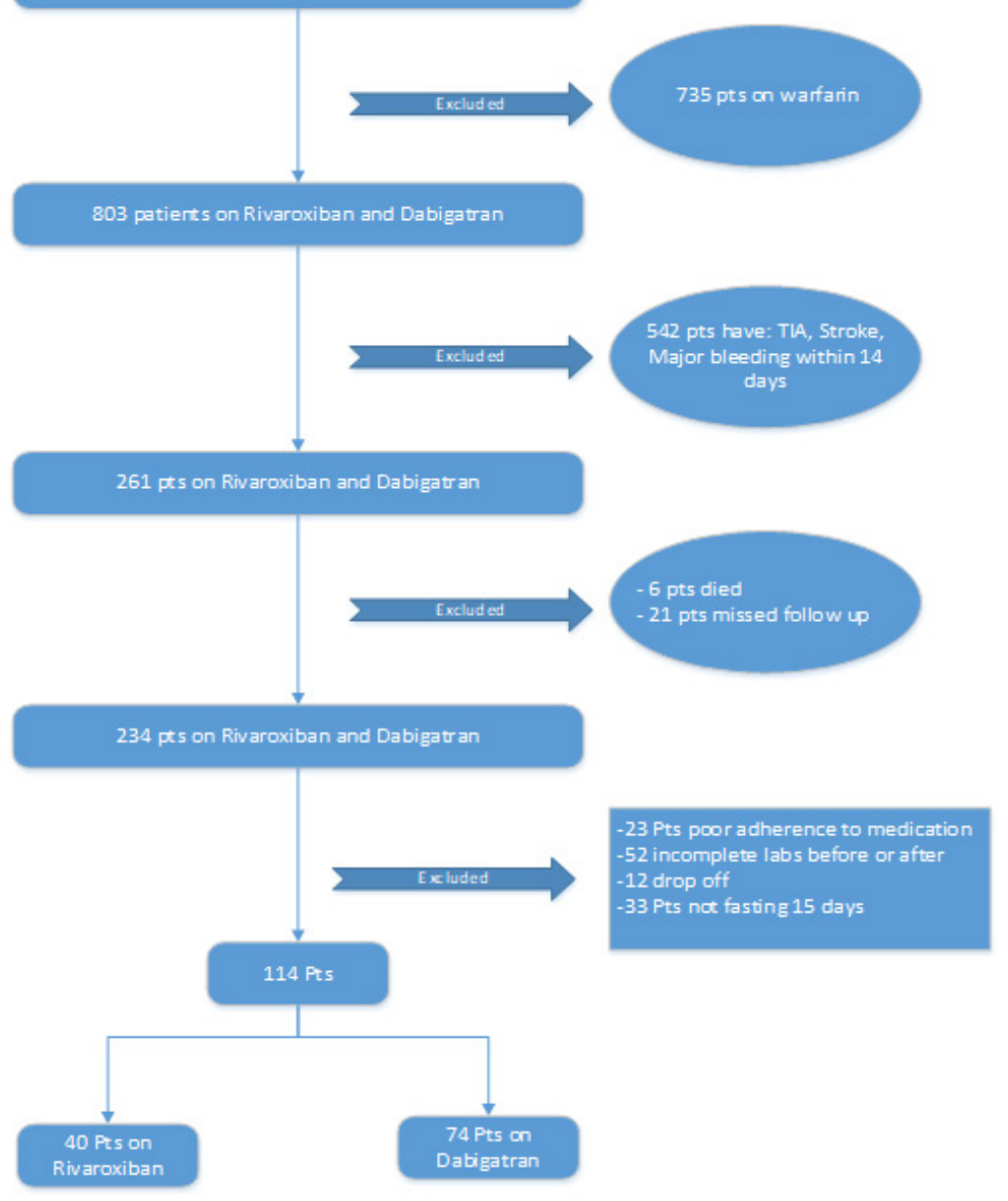

Figure 1: The demography of the sample size excluded.

TIA : Transient Ischaemic Attack.

Pts : Patients. 
Table 1: patient population demographic characteristics.

\begin{tabular}{|c|c|c|}
\hline 1. & Rivaroxiban & Dabigatran \\
\hline N & 40 & 74 \\
\hline Age & 65.5 & 65.5 \\
\hline F & $58 \%$ & $42 \%$ \\
\hline BMI & $42 \%$ & $58 \%$ \\
\hline Atrial Fibrillation & 28.9 & 31.4 \\
\hline CHA2 DS2 VASc Score & $85 \%$ & $99 \%$ \\
\hline $\begin{array}{c}\text { Previous stroke or transient isch- } \\
\text { emic attack }\end{array}$ & 1 & 1 \\
\hline Prior myocardial infarction & $28 \%$ & $5 \%$ \\
\hline Previous PCI & $8 \%$ & $4 \%$ \\
\hline $\begin{array}{c}\text { Previous coronary artery bypasses } \\
\text { surgery (CABG) }\end{array}$ & $8 \%$ & $8 \%$ \\
\hline Heart failure & $58 \%$ & $12 \%$ \\
\hline Diabetes mellitus & $63 \%$ & $55 \%$ \\
\hline Hypertension & $83 \%$ & $73 \%$ \\
\hline Chronic Liver disease & $0 \%$ & $0 \%$ \\
\hline
\end{tabular}

Table 2: patient population descriptions between to arms of the study.

\begin{tabular}{|c|c|c|}
\hline & Rivaroxiban & Dabigatran \\
\hline Stroke & $0 \%$ & $1 \%$ \\
\hline Bleeding & $0 \%$ & $4 \%$ \\
\hline Myocardial infarction & $0 \%$ & $0 \%$ \\
\hline Pulmonary embolism & $0 \%$ & $0 \%$ \\
\hline Death & $5 \%$ & $0 \%$ \\
\hline
\end{tabular}

Table 3: Laboratory Findings Comparison Before and After Fasting in Patients Receiving Rivaroxaban

\begin{tabular}{|c|c|c|c|}
\hline \multicolumn{4}{|c|}{ Variable } \\
\hline PT & Mean & SD & P-Value \\
\hline Before Fasting & 18.5 & 5.93 & 0.89 \\
\hline After Fasting & 18.54 & 4.88 & \\
\hline PTT & & & \\
\hline Before Fasting & 41.87 & 8.23 & 0.76 \\
\hline After Fasting & 42.18 & 7.74 & \\
\hline INR & & & \\
\hline Before Fasting & 1.48 & 0.6 & 0.65 \\
\hline After Fasting & 1.46 & 0.47 & \\
\hline Urea & & & \\
\hline Before Fasting & 9.11 & 6.74 & 0.44 \\
\hline After Fasting & 8.6 & 4.88 & \\
\hline Creatinine & & & \\
\hline Before Fasting & 94.69 & 37.97 & 0.24 \\
\hline After Fasting & 98.01 & 39.47 & \\
\hline
\end{tabular}

*Significant at level $\leq 0.05$.
Table 4: Laboratory Findings Comparison Before and After Fasting in Patients Receiving Dabigatran.

\begin{tabular}{|c|c|c|c|}
\hline \multicolumn{4}{|c|}{ Variable } \\
\hline & Mean & SD & P-Value \\
\hline \multicolumn{4}{|l|}{ PT } \\
\hline Before Fasting & 17.15 & 4.74 & 0.34 \\
\hline After Fasting & 17.47 & 4.37 & \\
\hline \multicolumn{4}{|l|}{ PTT } \\
\hline Before Fasting & 48.49 & 13.55 & $0.01^{*}$ \\
\hline After Fasting & 54.35 & 16.93 & \\
\hline \multicolumn{4}{|l|}{ INR } \\
\hline Before Fasting & 1.28 & 0.25 & 0.88 \\
\hline After Fasting & 1.27 & 0.24 & \\
\hline \multicolumn{4}{|l|}{ Urea } \\
\hline Before Fasting & 25.98 & 67.85 & 0.09 \\
\hline After Fasting & 7 & 7.47 & \\
\hline \multicolumn{4}{|l|}{ Creatinine } \\
\hline Before Fasting & 79.84 & 56.56 & 0.71 \\
\hline After Fasting & 76.41 & 26.6 & \\
\hline
\end{tabular}

*Significant at level $\leq 0.05$.

\section{Conclusion}

The data shows no clinical significant between the patients who received DOACs before and after Ramadan (Fasting) that's mean the direct oral anticoagulant (DOACs) are effective and safe to be used in Ramadan for non-valvular atrial fibrillation regardless the dose frequency of anticoagulants, further studies are needed to support these findings in non-valvular atrial fibrillation and other indications $[28,29]$.

\section{References}

1. Ziaee V, Razaei M, Ahmadinejad Z (2006) The changes of metabolic profile and weight during Ramadan fasting. Singapore Med J 47(5): 409-414.

2. Trepanowski JF, Bloomer RJ (2010) The impact of religious fasting on human health. Nutr J 9: 1-9.

3. Chennaoui M (2009) Effects of Ramadan fasting on physical performance and metabolic, hormonal, and inflammatory parameters in middle-distance runners. Appl Physiol Nutr Metab 34(4): 587-594.

4. Boroumand N, Hashemy SI (2015) The Effect of Ramadan Fasting on Endocrine System. J Fasting Health 3(4): 148-155.

5. Aybak M, Türkoğlu A, Sermet A, Denli O (1996) Effect of Ramadan fasting on platelet aggregation in healthy male subjects. Eur J Appl Physiol Occup Physiol 73(6): 552-526.

6. Mrityunjay, Khajuria V, Akhter P (2013) Effects of ramadan fasting on cardiovascular and biochemical parameters. Ind J Comm Health 25(4): 460-464.

7. Alluqmani WS (2019) Exploring Drug-Related Problems in Diabetic Patients during Ramadan Fasting in Saudi Arabia: A Mixed-Methods Study. Int J Environ Res Public Health 16(3): 499.

8. Aurigemma BK, Gaasch WH. Antithrombotic therapy in patients with prosthetic heart valves. 
9. Holmes MV, Hunt BJ, Shearer MJ (2012) The role of dietary vitamin K in the management of oral vitamin K antagonists. Blood Rev 26(1): 1-14.

10. Leiper J, Molla A, Molla A (2003) Effects on health of fluid restriction during fasting in Ramadan. Eur J Clin Nutr 57: S30-S38.

11. Kara E, Sahin OZ, Kizilkaya B, Ozturk B, Pusuroglu G, et al. (2017) Fasting in Ramadan is not associated with deterioration of chronic kidney disease: A prospective observational study. Saudi J Kidney Dis Transpl 28(1): 68-75.

12. Matter YE, Sheashaa HA, Refaie AF (2018) Effect of Ramadan fasting on patients with different kidney diseases: An updated review. J Egypt Soc Nephrol Transplant 18: 1-5.

13. Ekrem Kara (2017) Fasting in Ramadan is Not Associated with Deterioration of Chronic Kidney Disease: A Prospective Observational Study, Saudi J Kidney Dis Transpl 28(1): 68-75.

14. Yazdeen, Abdullah, Hummadi, Mutaz, Al-Tawil, et al. (2017) Association between Ramadan Fasting and cerebrovascular diseases. Zanco Journal of Medical Sciences 21(3): 1853-1858.

15. Atrial fibrillation (AF) and stroke guideline, Stroke Association 2019 Version 4

16. Wolf PA, Abbott RD, Kannel WB (1987) Atrial fibrillation: A major contributor to stroke in the elderly: the Framingham Study. Arch Intern Med 147(9): 561-564.

17. January CT, Wann LS, Calkins H, Lin Y Chen, Joaquin E Cigarroa, et al. (2019) 2019 AHA/ACC/HRS Focused Update of the 2014 AHA/ACC/ HRS Guideline for the Management of Patients With Atrial Fibrillation A Report of the American College of Cardiology/American Heart Association Task Force on Clinical Practice Guidelines and the Heart Rhythm Society. J Am Coll Cardiol 74(4): 599.

18. Alghamdi (2018) Effect of Ramadan Fasting on the International Normalized Ratio in Patients with Mechanical Prosthetic Heart Valves. Ulutas Med J 4(2):78-84.
19. Lai YF, Cheen MHH, Lim SH, Yeo FHI, Nah SC, et al. (2014) The effects of fasting in Muslim patients taking warfarin. J Thromb Haemost 12(3): 349-354.

20. Awiwi 0 (2017) The effects of Ramadan fasting on patients with prosthetic heart valve taking warfarin for anticoagulation. J Saudi Heart Assoc 29(1): 1-6.

21. Long JE (2016) Morning vaccination enhances antibody response over afternoon vaccination: A cluster-randomised trial. Vaccine 34(24): 2679-2785.

22. Knopp RH (1999) Drug treatment of lipid disorders. New Engl J Med 341: 498-511.

23. Mohawk JA (2012) Central and peripheral circadian clocks in mammals. Annu Rev Neurosci 35: 445-62.

24. Babineaux SM, Toaima D, Boye KS (2015) Multi-country retrospective observational study of the management and outcomes of patients with Type 2 diabetes during Ramadan in 2010 (CREED). Diabet Med 32(6): 819-828

25. Swerdel JN (2017) Association Between Dehydration and Short-Term Risk of Ischemic Stroke in Patients with Atrial Fibrillation. Trans Stroke Res 8(2): 122-130.

26. Selçuk Çomo (2003) Effects of Ramadan Fasting on Stroke. Turk J Med Sci 33: 237-241.

27. Bener A (2006) Is there any effect of Ramadan fasting on stroke incidence? Singapore Med J 47(5): 404-408.

28. Wolf PA, Abbott RD, Kannel WB (1991) Atrial fibrillation as an independent risk factor for stroke: the Framingham Study. Stroke 22(8): 983-988.

29. Lévi $F$ (2007) Implications of circadian clocks for the rhythmic delivery of cancer therapeutics. Adv Drug Deliv Rev 59(9-10): 1015-1035.

Your next submission with Juniper Publishers
will reach you the below assets
- Quality Editorial service
- Swift Peer Review
- Reprints availability
- E-prints Service
- Manuscript Podcast for convenient understanding
- Global attainment for your research
- Manuscript accessibility in different formats
( Pdf, E-pub, Full Text, Audio)
- Unceasing customer service
Track the below URL for one-step submission
https://juniperpublishers.com/online-submission.php

